\title{
Characteristics of abnormal serum creatine kinase-MB levels in children with COVID-19
}

\author{
Juan-Juan Wang ${ }^{1} \cdot$ Zhao Hu$^{2} \cdot$ Jian-Ying Chen ${ }^{3}$ (])
}

Received: 25 August 2020 / Accepted: 26 November 2020 / Published online: 19 April 2021

(c) Children's Hospital, Zhejiang University School of Medicine 2021

Severe acute respiratory syndrome coronavirus 2 (SARS$\mathrm{CoV}-2)$ targets angiotensin-converting enzyme- 2 on host cells and attacks various tissues including the heart and vasculature [1, 2]. Increasing evidence has shown that considerable numbers of patients with coronavirus disease 2019 (COVID-19) suffer from cardiovascular injury [3, 4]. Creatine kinase-MB (CK-MB) is mostly found in the myocardium and is a diagnostic marker for myocardial damage [5]. Here, we conducted a retrospective study of children with COVID-19 that were hospitalized in Wuhan Children's Hospital from 26 January to 24 March 2020. We described the epidemiological and clinical characteristics of infected children with normal or elevated levels of serum CK-MB in Wuhan during the early stage of the COVID-19 pandemic. Laboratory measures were obtained 1-2 days after hospitalization.

Of 243 pediatric patients, 103 (42.4\%) cases were identified with elevated levels of serum CK-MB. The mean age of patients with elevated CK-MB was 39.4 months, whereas the mean age of children with normal serum levels of CK-MB was 110.6 months. A higher proportion of younger children had elevated CK-MB (64.1\% vs. $8.6 \%$ under 3 years old, $P<0.001$ ). Regarding symptoms in the two groups, $89.3 \%$ of patients with elevated CK-MB had fever or cough compared with $51.5 \%$ of patients with normal serum levels of CK-MB

Jian-Ying Chen

unionchen@hust.edu.cn

1 Department of Endocrinology, Rheumatology and Immunology, Anhui Provincial Children's Hospital, Hefei, China

2 Department of Rheumatology and Immunology, Wuhan Children's Hospital, Tongji Medical College, Huazhong University of Science and Technology, Wuhan, China

3 Department of Gastrointestinal Surgery, Union Hospital, Tongji Medical College, Huazhong University of Science and Technology, Wuhan 430022, China having fever or cough. Patients with elevated CK-MB were more likely to have gastrointestinal symptoms ( $17.5 \%$ vs. $5.0 \%, P=0.0016)$. Laboratory test data further confirmed that COVID-19 patients with elevated CK-MB were more likely to have liver damage ( $47.6 \%$ vs. $11.4 \%, P<0.001)$ and pneumonia complications $(67.0 \%$ vs. $40.7 \%, P<0.001)$ (Table 1).

Pediatric patients with elevated CK-MB presented higher numbers of white blood cells $(6.932 \pm 0.176$ vs. $\left.8.182 \pm 0.311 \times 10^{9} / \mathrm{L}, P<0.001\right)$ and lymphocytes $\left(2.661 \pm 0.082\right.$ vs. $\left.4.147 \pm 0.203 \times 10^{9} / \mathrm{L}, P<0.001\right)$ and higher serum levels of cytokines [interleukin (IL)$6: 5.106 \pm 0.491$ vs. $12.810 \pm 3.195 \mathrm{pg} / \mathrm{mL}, P=0.0034$; interferon- $\gamma(\mathrm{IFN}-\gamma): 3.731 \pm 0.478$ vs. $6.050 \pm 1.028 \mathrm{pg} /$ $\mathrm{mL}, P=0.0232]$. B lymphocyte counts in children with elevated CK-MB were approximately twofold higher than those in patients with normal serum levels of CK-MB $\left(569 \pm 33\right.$ vs. $\left.1019 \pm 78 \times 10^{9} / \mathrm{L}, P<0.001\right)$. The duration of viral shedding from symptom onset to negative of RT-PCR test on nasopharyngeal swabs was shorter in children with elevated CK-MB $(16.540 \pm 1.049$ vs. $13.850 \pm 0.648$ days, $P=0.0254)$ (Table 1).

Although the infection rate of SARS-CoV-2 has been lower in children than in adults [6], an increasing number of pediatric cases have been confirmed worldwide in this ongoing pandemic. Cardiovascular complications are related to adverse clinical outcomes of adult COVID-19 patients, and myocardial damage is strongly associated with the increasing mortality of these patients $[7,8]$. However, the features of children with COVID-19 who suffered from myocardial injuries have seldom been reported. Here, we showed that $42.4 \%$ of pediatric patients with COVID-19 had abnormally high levels of serum CK-MB, which was consistent with Wang et al.'s report [8]. CK-MB is predominant in the myocardium but not in skeletal muscle and is the secondary substitute for troponins as a marker to diagnose acute myocardial infarction. As such, an increase in serum CK-MB may suggest 
Table 1 Clinical characteristics of COVID-19 children with or without elevated serum creatine kinase-MB

\begin{tabular}{|c|c|c|c|}
\hline Variables & Without ESC $(n=140)$ & With ESC $(n=103)$ & $P$ \\
\hline \multicolumn{4}{|l|}{ Sex, $n(\%)$} \\
\hline Male & $90(64.3)$ & $61(59.2)$ & \multirow[t]{2}{*}{0.4214} \\
\hline Female & $50(35.7)$ & $42(40.8)$ & \\
\hline Age (mon), mean \pm SEM & $110.6 \pm 3.997$ & $39.4 \pm 4.452$ & $<0.001$ \\
\hline \multicolumn{4}{|l|}{ Age distribution, $n(\%)$} \\
\hline $1-3$ mon & $2(1.4)$ & $17(16.5)$ & $<0.001$ \\
\hline $3-12$ mon & $5(3.6)$ & $27(26.2)$ & $<0.001$ \\
\hline $1-3 y$ & $5(3.6)$ & $22(21.4)$ & $<0.001$ \\
\hline $3-6 y$ & $13(9.3)$ & $17(16.5)$ & 0.0909 \\
\hline $6-12 y$ & $73(52.1)$ & $16(15.5)$ & $<0.001$ \\
\hline$>12 y$ & $42(30.0)$ & $4(3.9)$ & $<0.001$ \\
\hline \multicolumn{4}{|l|}{ Symptoms, $n(\%)$} \\
\hline Fever & $39(27.9)$ & $47(45.6)$ & 0.0042 \\
\hline Cough & $33(23.6)$ & $45(43.7)$ & $<0.001$ \\
\hline GI symptoms & $7(5.0)$ & $18(17.5)$ & 0.0016 \\
\hline Liver damage, $n(\%)$ & $16(11.4)$ & 49 (47.6) & $<0.001$ \\
\hline \multicolumn{4}{|l|}{ Type of severity of illness, $n(\%)$} \\
\hline Symptom-free & $54(38.6)$ & $15(14.6)$ & $<0.001$ \\
\hline Upper respiratory infection & $27(19.3)$ & $17(16.5)$ & 0.5780 \\
\hline Mild pneumonia & $57(40.7)$ & $69(67.0)$ & $<0.001$ \\
\hline Severe & $2(1.4)$ & $2(1.9)$ & 0.7560 \\
\hline \multicolumn{4}{|l|}{ Laboratory parameters, mean \pm SEM } \\
\hline White blood cell count $\left(\times 10^{9} / \mathrm{L}\right)$ & $6.932 \pm 0.176(n=139)$ & $8.182 \pm 0.311(n=101)$ & $<0.001$ \\
\hline Neutrophil count $\left(\times 10^{9} / \mathrm{L}\right)$ & $3.605 \pm 0.152(n=139)$ & $3.262 \pm 0.260(n=101)$ & 0.2298 \\
\hline Lymphocyte count $\left(\times 10^{9} / \mathrm{L}\right)$ & $2.661 \pm 0.082(n=139)$ & $4.147 \pm 0.203(n=101)$ & $<0.001$ \\
\hline Neutrophil count (\%) & $50.530 \pm 1.085(n=139)$ & $37.930 \pm 1.815(n=101)$ & $<0.001$ \\
\hline Lymphocyte count (\%) & $39.520 \pm 1.041(n=139)$ & $52.150 \pm 1.851(n=101)$ & $<0.001$ \\
\hline CD3 + lymphocyte count $\left(\times 10^{9} / \mathrm{L}\right)$ & $2051 \pm 81(n=110)$ & $3176 \pm 168(n=79)$ & $<0.001$ \\
\hline CD4 + lymphocyte count $\left(\times 10^{9} / \mathrm{L}\right)$ & $1007 \pm 47(n=110)$ & $1798 \pm 103(n=79)$ & $<0.001$ \\
\hline CD8 + lymphocyte count $\left(\times 10^{9} / \mathrm{L}\right)$ & $831 \pm 47(n=110)$ & $1113 \pm 62(n=79)$ & $<0.001$ \\
\hline CD19+ lymphocyte count $\left(\times 10^{9} / \mathrm{L}\right)$ & $569 \pm 33(n=110)$ & $1019 \pm 78(n=79)$ & $<0.001$ \\
\hline Interleukin-6 (pg/mL) & $5.106 \pm 0.491(n=121)$ & $12.810 \pm 3.195(n=77)$ & 0.0034 \\
\hline Interleukin-10 (pg/mL) & $3.848 \pm 0.184(n=122)$ & $10.370 \pm 4.248(n=77)$ & 0.0549 \\
\hline Interferon- $\gamma(\mathrm{pg} / \mathrm{mL})$ & $3.731 \pm 0.478(n=122)$ & $6.050 \pm 1.028(n=77)$ & 0.0232 \\
\hline Tumor necrosis factor- $\alpha(\mathrm{pg} / \mathrm{mL})$ & $1.956 \pm 0.147(n=122)$ & $2.435 \pm 0.399(n=77)$ & 0.1934 \\
\hline Interleukin-2 (pg/mL) & $1.550 \pm 0.062(n=122)$ & $1.694 \pm 0.128(n=77)$ & 0.2918 \\
\hline Interleukin-4 (pg/mL) & $2.856 \pm 0.120(n=122)$ & $2.948 \pm 0.248(n=77)$ & 0.7133 \\
\hline Lactate dehydrogenase (U/L) & $212.700 \pm 4.251(n=140)$ & $343.200 \pm 17.360(n=103)$ & $<0.001$ \\
\hline Lactate dehydrogenase-1 (U/L) & $42.650 \pm 0.933(n=139)$ & $78.430 \pm 5.027(n=101)$ & $<0.001$ \\
\hline Creatine kinase (U/L) & $94.630 \pm 3.804(n=140)$ & $222.200 \pm 71.990(n=103)$ & 0.0403 \\
\hline Creatine kinase-MB (U/L) & $18.030 \pm 0.345(n=140)$ & $50.750 \pm 5.494(n=103)$ & $<0.001$ \\
\hline Alanine aminotransferase (U/L) & $19.720 \pm 1.602(n=140)$ & $32.140 \pm 6.049(n=103)$ & 0.0252 \\
\hline Aspartate aminotransferase (U/L) & $27.010 \pm 1.751(n=140)$ & $52.890 \pm 7.912(n=103)$ & $<0.001$ \\
\hline D-Dimer (mg/L) & $0.280 \pm 0.047(n=111)$ & $1.349 \pm 0.595(n=70)$ & 0.0257 \\
\hline Duration of viral shedding (d) & $16.540 \pm 1.049(n=61)$ & $13.850 \pm 0.648(n=74)$ & 0.0254 \\
\hline
\end{tabular}

GI symptoms include anorexia, diarrhea, vomit, and abdominal pain. Duration of viral shedding is the time from symptom onset to negative of RT-PCR test on nasopharyngeal swab. COVID-19 coronavirus disease 2019, ESC elevated serum creatine kinase-MB, GI gastrointestinal, $S E M$ standard error of mean 
the possibility of myocardial damage by SARS-CoV-2, and additional investigation of cardiac biomarkers and functions should be performed. Our results also demonstrated that pediatric patients with abnormal levels of serum CK-MB experienced a higher immune response, as they exhibited higher levels of cytokines, such as IL- 6 and IFN- $\gamma$, and great numbers of immune cells, especially including CD3, CD4 and CD8 T lymphocytes and CD19 B lymphocytes. Hyperinflammatory cytokine storms are considered to play a key role in the disease process of COVID-19 [9]. Aggressive inflammatory responses strongly lead to injury of healthy cells adjacent to the site of infection, which further exacerbates organ damage caused by the elimination of infected cells [10]. This effect might be one potential reason that pediatric COVID-19 patients with elevated serum CK-MB more frequently experienced impairment of multiple organs, including the heart, liver and gastrointestinal tract as shown by elevated function biomarkers or corresponding symptoms. However, lymphocytes, including $\mathrm{T}$ cells and $\mathrm{B}$ cells, play critical roles in the antiviral immune response, and a higher immune response may also result in a shorter duration of viral shedding, as shown in the patients with elevated levels of serum CK-MB.

In conclusion, elevated serum CK-MB might indicate more organ damages and a higher immune response in children with COVID-19, so additional monitoring should be conducted on these patients with abnormal serum CK-MB levels.

Acknowledgements We thank the computer center of Wuhan children's Hospital for its support and also thank Wei Li, Xing-Hua Liu, and Yun-Qiao Li from Union Hospital, Tongji Medical College, Huazhong University of Science and Technology for helping complete this project.

Author contributions WJJ and $\mathrm{HZ}$ contributed equally to this work. WJJ collected the clinical data, conceptualized and designed the project, drafted the manuscript, and analyzed the data. HZ collected the clinical data and analyzed the data. CJY had full access to all of the data in the study and take responsibility for the integrity of the data, and revised the manuscript for important intellectual content. All the authors read and corrected the manuscript and approved the final version.

\section{Compliance with ethical standards}

Ethical approval The study was carried out in accordance with the Declaration of Helsinki and approved by the Ethics Commission of Huazhong University of Science and Technology.

Conflict of interest The authors have no conflict of interest to declare.

\section{References}

1. Hoffmann M, Kleine-Weber H, Schroeder S, Krüger N, Herrler T, Erichsen S, et al. SARS-CoV-2 cell entry depends on ACE2 and TMPRSS 2 and is blocked by a clinically proven protease inhibitor. Cell. 2020;181:271-80.

2. Zou X, Chen K, Zou J, Han P, Hao J, Han Z. Single-cell RNAseq data analysis on the receptor ACE2 expression reveals the potential risk of different human organs vulnerable to 2019-nCoV infection. Front Med. 2020;14:185-92.

3. Guo T, Fan Y, Chen M, Wu X, Zhang L, He T, et al. Cardiovascular implications of fatal outcomes of patients with coronavirus disease 2019 (COVID-19). JAMA Cardiol. 2020;5:811-8.

4. Inciardi RM, Lupi L, Zaccone G, Italia L, Raffo M, Tomasoni D, et al. Cardiac involvement in a patient with coronavirus disease 2019 (COVID-19). JAMA Cardiol. 2020;5:819-24.

5. Park DW, Kim YH, Yun SC, Ahn JM, Lee JY, Kim WJ, et al. Frequency, causes, predictors, and clinical significance of periprocedural myocardial infarction following percutaneous coronary intervention. Eur Heart J. 2013;34:1662-9.

6. Gudbjartsson DF, Helgason A, Jonsson H, Magnusson OT, Melsted P, Norddahl GL, et al. Spread of SARS-CoV-2 in the Icelandic population. N Engl J Med. 2020;382:2302-15.

7. Sabatino J, De Rosa S, Di Salvo G, Indolfi C. Impact of cardiovascular risk profile on COVID-19 outcome. A meta-analysis. PLoS One. 2020;15:e237131.

8. Wang D, Hu B, Hu C, Zhu F, Liu X, Zhang J, et al. Clinical characteristics of 138 hospitalized patients with 2019 novel coronavirus-infected pneumonia in Wuhan, China. JAMA. 2020;323:1061-9.

9. Turnquist C, Ryan BM, Horikawa I, Harris BT, Harris CC. Cytokine storms in cancer and COVID-19. Cancer Cell. 2020;38:598-601.

10. Merad M, Martin JC. Pathological inflammation in patients with COVID-19: a key role for monocytes and macrophages. Nat Rev Immunol. 2020;20:355-62.

Publisher's Note Springer Nature remains neutral with regard to jurisdictional claims in published maps and institutional affiliations. 